\section{Archaeology and metal analysis}

Three years ago (September I970, 207) we published an article by $E$. A. Slater and $¥ . A$. Charles which expressed certain misgivings about the grouping of analyses, used in $S A M I$ and $S A M 2$, based on the amount of bismuth present. We thought this called for a reply and the following note is jointly by Professor Dr E. Sangmeister (Freiburg $i \mathrm{Br}$.) and Dr H. Otto (Frankfurt). Dr Slater and $\mathrm{Mr}$ Charles add a brief rejoinder in which they explain why they are still unrepentant.

Since the comments by E. A. Slater and J. A. Charles appear to concern a significant part of our study, they call for a reply.

Slater and Charles base their argument principally on the long-established fact that the solubility of bismuth in copper is very low. Consequently, at certain bismuth levels, we may have to contend with segregation phenomena, which would make it more difficult to obtain a representative metal sample, and would thus affect the reliability of any statistically based classification.

\section{ARCHAEOLOGICAL OBSERVATIONS}

Slater and Charles's article reports the first experimental proof that segregation phenomena do occur in copper containing bismuth when it is cast in two-piece moulds, under conditions which may be assumed typical for prehistoric metallurgy. To complete the evidence, however, we also need experiments to show whether similar results are found in castings from open clay or stone moulds laid horizontally, or from sand-casting. There has been scarcely any investigation relating segregation effects to different conditions of metal cooling and solidification (when casting in horizontally-laid moulds, for example, or with more rapid solidification); nothing is known about what variations in bismuth concentration may ensue. The majority of the objects we studied were made by much simpler processes; castings from two-piece moulds occur less frequently.

\section{METALLURGICAL OBSERVATIONS}

As is well known, bismuth is fully soluble in copper up to $0.002 \%$. The division between SAM I and SAM 2 groupings based on a bismuth content above or below this figure is therefore incontestable. The same is true of the limit of $0.008 \%$, which we also utilize, since Slater and Charles's results show that with a bismuth component of the order of $0.007 \%$ readings from different parts of the same casting differ from each other by less than $10 \%$. This is quite within the precision of the analysis methods we used. Only in the region of our further limit of $0.02 \%$ could segregation effects lead to mistaken classification. It should however be recalled that our groupings are first derived primarily from the proportions of arsenic and antimony and from nickel, and are not based on bismuth levels alone. These are considered only for sub-division of groups established in this way. Furthermore, this sub-division concerns only a few groups, which are already easily distinguishable from their particular combination of elements.

Generally, small objects cool down rapidly after casting, especially when shallow moulds are used. Polished sections of such objects have shown that the less soluble components are very evenly distributed. Apparently there is insufficient time for enrichment by 'sinking', or from segregation into certain areas. Thus the standard amount of 0.04 grammes, which we take as a typical sample, should be approximately representative.

All the arguments and counter-arguments, moreover, relate to metal systems of two elements. Experimental evidence for segregation of the various proven elements in more complex systems is not yet available. None is mentioned 


\section{ANTIQUITY}

by Slater and Charles. Multiple-element systems are encountered, for example, in group AI, which contains up to $9.5 \%$ impurities: arsenic, antimony, silver and nickel; or in groups $\mathrm{C}_{2} / \mathrm{C}_{2} \mathrm{C}$, with up to $7.5 \%$ arsenic, antimony and silver. The behaviour of bismuth in such alloys has not yet been determined, and it needs investigation.

\section{STATISTICAL OBSERVATIONS}

The 'limits' given in Diagram I of SAM 2 represent statistically minimum values for division lines between groups. They should be regarded merely as the 'specifications of imprecision' deriving from statistical analysis. We therefore also gave (in Table $\mathrm{I}$ of the same volume) the corresponding maxima, which are to be read more exactly. To either side of a 'limiting value' lies a 'no-man's land', into which fall those analyses which can be assigned to neither one group nor the other. This is understood statistical procedure, and was repeatedly referred to in the text of our volumes. The variations in bismuth reported by Slater and Charles within each of their specimens always fall within the range of this 'no-man's land'. Thus, should a specimen approach the limiting value (between, say, $0.02 \%$ and $0.028 \%$ ), it is then a border-line case, since the upper range of values begins only at $0.04 \%$ (for $\mathrm{C}_{2}$, for example).

Using these criteria, it is never possible to assign to a particular group on the basis of a single analysis. Group determination is possible only from a number of analyses.

If bismuth segregation has been a significant feature in copper, or copper alloys, as Slater and Charles would suggest, we may ask how it has been possible to distinguish clear statistical groupings, such as $\mathrm{C}_{2}$, and to determine their bismuth content. If we had to contend with varying concentrations of bismuth in different parts of the casting, brought about by segregation, then a single sample analysis could not be representative. If this were so, however, it should also be impossible to obtain frequency distributions which satisfy a normal Gaussian curve; bismuth values would have to be scattered across the range of readings. Thus, when normal distributions are in fact found, as for example in $\mathrm{C}_{2}$ as shown in FIG. 2, this calls for explanation:

(a) either segregation was precluded by the casting procedure used in antiquity (rapid cooling);

(b) alternatively, bismuth segregation in more complex alloys does not occur in the same manner as seems to have been demonstrated in the copper-bismuth system;

(c) again, sampling methods might have restored some sort of comparability (taking the sample each time from the thickest part of the object might possibly encounter similar conditions as regards segregation).

If either (a) or (b) is true, then the statistical groups would in fact be representative of the metal used. In the case of the third possibility (c), the metal used might have been of a different composition, with respect to its bismuth content. Despite this, however, the validity of the groupings would not be in doubt.

One further point is relevant. The revision of groupings proposed by Slater and Charles would, as we have argued, concern only the division at $0.02 \%$. This means that the groups $\mathrm{C}_{2}, \mathrm{C}_{2} \mathrm{AB}$ and $\mathrm{C}_{2} \mathrm{C}$ (which we shall henceforth call the ' $\mathrm{C} 2$ groups') on the one hand, and group $\operatorname{ErI}_{I} \mathrm{~B}$ on the other, would be involved. Other groups are not comparable, since their arsenic, antimony and nickel values are different. Group EII A, however, can be compared, though its bismuth values fall below $0.002 \%$ and thus are clearly distinguishable. A division at or about $0.02 \%(-7$ in the graph) will cut off one section of the bismuth curve, namely that which does not satisfy the normal distribution (FIG. $\mathrm{r}$ ).

The significance of this is as follows. The $\mathrm{C}_{2}$ groups are made from a metal whose known bismuth values are truly representative, since they follow a normal distribution. EI $\mathrm{A}$ is a distinct group, for which bismuth segregation has no relevance. EII B would then constitute a separate group, which belongs with neither of these divisions. It is certainly something 
NOTES AND NEWS

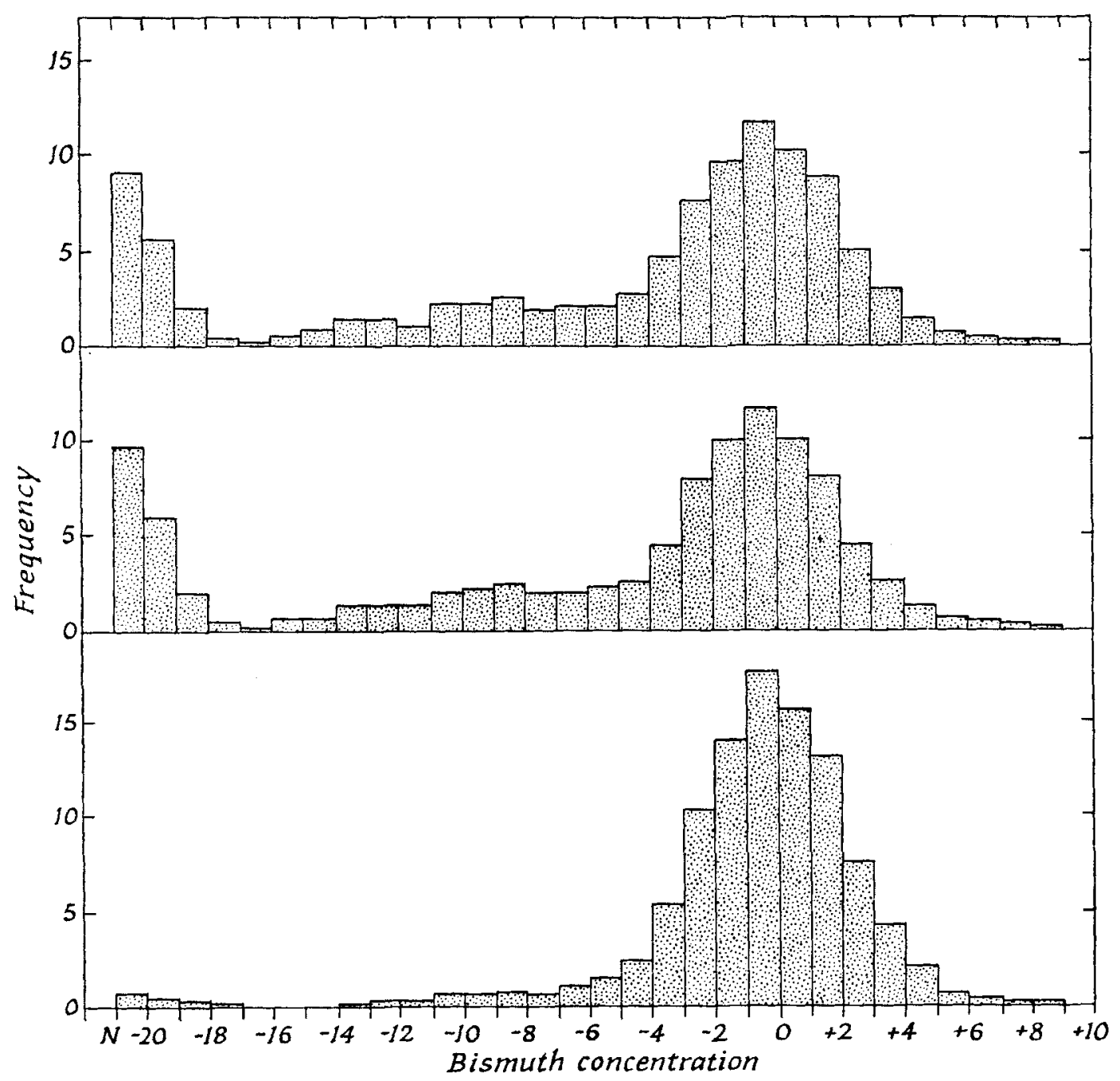

Fig. I. Distribution of bismuth in analyses of the material groups EII A, EII B, C2, C2 A and C2 C. Classifications as in SAM 2. Top: all analyses from the Early Bronze Age (= Reinecke's Bronze Age $A I$; phases $I-3$ of $R$. Christlein); centre: all analyses of objects from the Copper and Early Bronze Ages; bottom: 'Osenhalsringe' (mostly ingots), analyses alone

distinct; and one must ask what it represents.

The $\mathrm{C}_{2}$ groups were used predominantly in the manufacture of Ösenringe. Is it possible that in utilizing these ingots for the production of other implements a process was used which accentuated bismuth segregation? (Perhaps by cooling the castings more slowly.) Group EII $B$ could then be a portion of $\mathrm{C} 2_{2}$, in which a normal distribution for bismuth values is no longer encountered, but rather an indeterminate scatter. Or again, could Er I B consist of Ei I A material which had absorbed bismuth during re-melting and alloying with other material? In this event also we should not expect to find bismuth values normally distributed. The numbers of Ösenringe are of interest for these questions. Of 2026 examples, 59 (or $3.8 \%$ ) belong in $\mathrm{Er}_{1} \mathrm{~B}$, and all the other in the $\mathrm{C}_{2}$ 


\section{ANTIQUITY}

groups. The proportion for all other objects from the earliest bronze age is $60 \mathrm{I}$ in $\mathrm{C}_{2}$ groups, and 493 , or $45 \%$, in $E_{I I} B$. These figures certainly support one or other of our proposals.

It should be obvious that fears that bismuth segregation effects might invalidate the material groups set out in SAM 2 have not proved justified. It must, admittedly, be emphasized that archaeologists must utilize these groupings in the sense they were intended, and published. Single analyses cannot be classified reliably, but only groups of analyses. Furthermore, as we have clearly stated, the material groups at best reflect metals which have been prepared 'from uniform processes and source materials'. This does not signifiy that each material group corresponds to one particular ore. It could correspond to a single ore, or to a combination of several. It might also represent a product in which characteristic changes have been introduced by working methods. We have attempted to interpret EI I B in this last way.

\section{E. A. Slater and $\mathcal{F}$. A. Charles write:}

(taking the arguments in order):

The phenomenon of segregation in castings has been widely investigated and documented in metallurgical literature, relating segregation effects to casting conditions (e.g. B. Chalmers, Principles of solidification, 1964; J. A. Charles, Archaeometry, 15, pt. I, 1973, 105-14). The experiments we carried out were designed to demonstrate the effect rather than prove its existence, which could have been predicted. It is true that differing mould materials, mould shape, and open or closed forms will alter the solidification process and vary the extent or pattern of segregation, but the results are, again, predictable from modern practice. In any case, the temperature gradient from the mould wall and the existence of varying patterns of solidification (i.e. columnar or equiaxed grains), so important in the context of macrosegregation, will partly depend also on the degree of superheat, i.e. the temperature from which the metal was cast. This we shall never know for ancient objects. There is really little point in going further in experimental study.
Existing metallurgical knowledge is sufficient to enable us to suggest in what circumstances segregation is likely to be a problem.

Contrary to the view of Otto and Sangmeister it is not only the $0.02 \% \mathrm{Bi}$ limit where our results impinge but also at the first division in SAM I at $0.08 \% \mathrm{Bi}$ and the minor division at $0.16 \% \mathrm{Bi}$ in SAM 2. In relation to the $0.02 \% \mathrm{Bi}$ division, which initially separates the most important groups, it is claimed that the division is primarily obtained on the $\mathrm{As}, \mathrm{Sb}$ and $\mathrm{Ni}$ contents. In fact the As> $>0.025 \%, \mathrm{Sb}>0.025 \%$ division is an arbitary one. For many of the objects it affects it could have been set as As $>\mathrm{I} \cdot 0 \%, \mathrm{Sb}>\mathrm{I} \cdot 0 \%$, and with almost full accuracy as As>0.1\%, Sb>0.1\%. It is difficult to see how, therefore, the objects have been brought into a group other than on the basis of the bismuth, as we claim.

The samplesize used by Otto and Sangmeister is minimal even in relation to local segregation at a small grain size, as obtained in a rapidlychilled casting. In the case of bismuth, however, there is always likely to be macrosegregation of last-freezing liquid to varying positions in the object where only multi-sampling can give an accurate sample for analysis.

Otto and Sangmeister do not appear to have read the text of our paper when they comment that our work relates to two-element systems. All our four reproduction axes were of tin bronze containing bismuth, with one containing lead also. There were, therefore, threecomponent systems and one a four-component system.

The statistical observations made are difficult to follow. The minimum and maximum values from Table I of SAM $2 \cdot 2$ are frequently well removed from the division values, but this is by no means always the case, e.g. CIB Bismuth, A Nickel, Ar Nickel, B2 Bismuth, FA Nickel, $\mathrm{FB}_{2}$ Silver, etc. It is still not clear to us how the extent of the 'no-man's land' is supposed to have been established. It seems to us that the correct approach must be wholly analytical, with accuracy limits for each element and its level of occurrence established by the possible errors which could arise from both the analysis method and the existence of non-representative 


\section{NOTES AND NEWS}

sample. Where analyses, with their range of confidence, straddle a division, in spite of clear divisions established on the bulk of results, they would have to be considered as being assigned to more than one group, with final association related to other factors of the archaeological context. It is perhaps significant that no account seems to have been taken of admitted analysis error limits in SAM I and SAM 2.

Most difficult of all, perhaps, is their statement that 'Using these criteria, it is never possible to assign to a particular group on the basis of a single analysis. Group determination is possible only from a number of analyses.' Many of the objects included in the groupings in SAM 2 are, in fact, stray finds. Surely they do not mean that the groups were primarily established from the archaeological context of the objects!

The reason that group $\mathrm{C}_{2}$ has arisen is because the objects here have a similar origin and an almost uniform composition, well within the limits set (Table I, SAM 2.2)-this is the way a group is established. The 'explanations' given are not relevant and do not, in any case, stand metallurgical scrutiny:

(a) Segregation is a function of the redistribution of solute arising under varying conditions of cooling,-rapid cooling, giving rise to non-equilibrium conditions, may result in greater interdendritic segregation, as for example in the case of inverse segregation $(\mathrm{H}$. McKerrell, PPS, 1973, 39).

(b) Segregation is more likely to occur in complex alloys. For example, in our fourelement system the lower melting points of the eutectic series of bismuth with lead and tin means that the freezing range is extended and the likelihood of macrosegregation increased.

(c) Clearly, multi-sampling gives the best

\section{Wessex as a social question}

The rich graves of the early second millennium $\mathrm{BC}$ in south Britain, termed the Wessex culture by Stuart Piggott (1938), are still the subject of controversy. The real nature of the material as a closely related assemblage is still in question as also its date and whether or not those who chance of a true analysis. Merely choosing a particular wall thickness will be of little help since the degree of segregation will not only be related to this but also to the pouring temperature of the metal, the conductivity and mass of the mould, the way in which the metal is introduced and feeds the mould and the position of the section in relation to the casting as a whole. The JSS material covers a very wide range in casting size and shape.

It is not clear to us what the argument is in relation to the ' $\mathrm{C2}$ ' groups in comparison with EII $A$ and EII B. We believe that it is a matter of fact that EI $\mathrm{B}$ metal is very similar to $C_{2}$, but that $E_{I I} A$ is in two distinct groups, one like A metal except for the nickel content, the other apparently individualistic.

Whether or not different measured analyses in terms of bismuth content arise from the mixing of sources or from remelting and alloying with other material, it is certain that melting in air should reduce the bismuth content, as in normal copper refining, and thus lessen the incidence of its variation by segregation. The accentuation of normal segregation by slow cooling is clearly possible, and in castings where this has occurred single samples are likely to be non-representative.

Our original paper was mainly concerned with the presentation of experimental evidence demonstrating the significance of segregation in castings in relation to the danger of basing analyses on single, small, samples where the results are to be used with a rigorous classification scheme. For well-understood metallurgical reasons, bismuth and lead are particularly liable to segregate and divisions made using such elements are liable to include error. We see no reason to modify our warning in response to this reply by Otto and Sangmeister.

used it were in contact with the Aegean world.

At the same time several points of agreement are emerging. In the first place it is clear that the sarsen structure of Stonehenge (IIIa) was built rather early. Christopher Hawkes has rightly stressed that there are no very strong 